\title{
An experimental study of fracture initiation mechanisms during hydraulic fracturing
}

\author{
Yan Tie*, Li Wei and Bi Xueliang \\ Heilongjiang, 163318, China \\ (C) China University of Petroleum (Beijing) and Springer-Verlag Berlin Heidelberg 2011
}

Key Laboratory of Enhanced Oil \& Gas Recovery, Ministry of Education, Northeast Petroleum University, Daqing,

\begin{abstract}
The mechanism of fracture initiation is the basic issue for hydraulic fracture technology. Because of the huge differences in fracture initiation mechanisms for different reservoirs, some successful fracturing techniques applied to porosity reservoirs are ineffectual for fractured reservoirs. Laboratory tests using a process simulation device were performed to confirm the characteristics of fracture initiation and propagation in different reservoirs. The influences of crustal stress field, confining pressure, and natural fractures on the fracture initiation and propagation are discussed. Experimental results demonstrate that stress concentration around the hole would significantly increase the fracture pressure of the rock. At the same time, natural fractures in the borehole wall would eliminate the stress concentration, which leads to a decrease in the fracture initiation pressure.
\end{abstract}

Key words: Hydraulic fracturing, porosity reservoir, fractured reservoir, fracture initiation, fracture propagation, simulation experiment

\section{Introduction}

Since its introduction into the Hugoton gas reservoir of Kansas in U.S.A. in 1947, hydraulic fracturing has been and will remain one of the important tools for improving well productivity. In order to improve the success rate and fracturing effect, several researchers investigated fracture initiation and propagation under different reservoir conditions. Hubbert and Willis (1957) proposed that the fracture would initiate and propagate in a particular direction, perpendicular to the minimum principal stress, and then a macro-crack would be created. They presented the first formula to calculate the fracture pressure. Thiercelin et al (1985) used a high-speed camera to record fracture propagation and quantitatively measure the fracture geometry. Their research showed that the fracture propagated following an elliptical shape in homogeneous materials. This conclusion was not applicable to heterogeneous interlayers with different horizontal stresses. Daneshy (1974) put forward that the hydraulic fractures initiated and propagated following the rule proposed by Hubbert and Willis (1957), but natural fractures in the formations would affect the propagation of hydraulic fractures. Blanton (1986) thought that the differential stress in the horizontal direction and included angle between the hydraulic fracture and the natural fracture were the major factors affecting the fracture strike and shape. Warpinski and Teufel (1987) conducted scaled laboratory experiments

*Corresponding author. email: yant@dqpi.edu.cn

Received April 4, 2010 to investigate the interaction between a hydraulic fracture and a natural fracture. They observed that shear failure of natural fractures happened easily when interference occurred between hydraulic fractures and natural fractures. Beugelsdijk et al (2000) believed that the horizontal stress difference and the tectonic stress difference might influence the fracture propagation and its geometries, and the effect of the latter was more notable. Yew and Li (Yew, 1992; Yew and Li, 1987) studied the fracturing of a deviated well. Chen et al (1995; 2000) and Zhang and Chen (2005) performed a series of large-scale tri-axial experiments to investigate the influence of natural fractures and earth stress on the induced fractures. Taking into account the influence of the natural fracture strike and dip, Jin et al (2005) proposed three initiation modes of hydraulic fractures on the borehole wall and corresponding computational models were built. Laboratory research into the mechanism of fracture propagation in fractured reservoirs showed that the horizontal stress difference and the angle of approach were the macro-parameters affecting the hydraulic fracture propagation in a normal stress regime, and the interfacial friction coefficient and dimensionless net pressure were the micro-parameters (Zhou et al, 2007). The influence of regional tectonic stress regime on the hydraulic fracture propagation was greater than that of the natural fractures. Yu et al (1994) performed detailed research into mechanisms of deviated well fracturing. In this study, the fracture initiation mechanisms in different reservoirs were studied using hydraulic fracturing tests, and the influences of the crustal stress field, the confining pressure, and natural fractures on the fracture initiation and propagation are discussed. 


\section{Experimental}

Large size synthetic rock specimens were prepared in a mold and the pre-fractures were simulated by placing one piece of A4 paper in the specimens. A hollow tube was put in the center of specimen to simulate the wellbore. The specimen was set up on hydraulic equipment to load triaxial stress. Water with red dye was injected into the specimen constantly through the hollow tube using a constant pressure pump, which was used to simulate gradually increasing pressure in the borehole. The rock would break when the fracture pressure was reached.

The reservoirs, in which hydraulic fracturing is an effective method for increasing well productivity, can be divided macroscopically into porous reservoirs and fractured reservoirs. A series of 8 hydraulic fracture tests was conducted to study the fracture initiation and propagation in these two reservoir types, and to analyze the fracturing azimuth and the influence of natural fractures on the initiation and propagation of hydraulically-induced fractures.

Eight concrete blocks were prepared in a mold $0.3 \mathrm{~m} \times 0.3 \mathrm{~m} \times 0.3 \mathrm{~m}$ to simulate porous and fractured reservoir rocks. Each concrete block contained a cylindrical cavity (50 $\mathrm{mm}$ long) and a steel tube $(10 \mathrm{~mm} \times 150 \mathrm{~mm})$, as shown in Fig. 1. The steel tube was cast in the concrete block, and 50 $\mathrm{mm}$ orifice was kept underneath the pipe to simulate the open hole section. A summary of their physical properties is given in Table 1.

Table 1 Specific parameters of eight specimens

\begin{tabular}{|c|c|c|c|c|c|}
\hline Specimen & $\begin{array}{l}\text { Pre-fracture } \\
\text { orientation }\end{array}$ & $\begin{array}{c}\text { Principal } \\
\text { stress } 1 \\
\mathrm{MPa}\end{array}$ & $\begin{array}{c}\text { Principal } \\
\text { stress } 2 \\
\mathrm{MPa}\end{array}$ & $\begin{array}{c}\text { Principal } \\
\text { stress } 3 \\
\mathrm{MPa}\end{array}$ & $\begin{array}{c}\text { Flow rate } \\
\mathrm{mL} / \mathrm{min}\end{array}$ \\
\hline $1 \#$ & - & 10 & 6 & 4 & 3.5 \\
\hline $2 \#$ & - & 6 & 10 & 4 & 3.5 \\
\hline $3 \#$ & - & 4 & 6 & 10 & 3.5 \\
\hline 4\# & - & 6 & 4 & 10 & 3.5 \\
\hline $5 \#$ & $\begin{array}{l}\text { Parallel to the central } \\
\text { injection tube }\end{array}$ & 6 & 4 & 10 & 3.5 \\
\hline $6 \#$ & $\begin{array}{c}\text { Parallel to the central } \\
\text { injection tube }\end{array}$ & 6 & 4 & 10 & 3.5 \\
\hline $7 \#$ & $\begin{array}{c}\text { Parallel to and } \\
\text { intersecting the } \\
\text { central injection tube }\end{array}$ & 6 & 10 & 4 & 3.5 \\
\hline $8 \#$ & $\begin{array}{l}\text { Perpendicular to } \\
\text { and intersecting the } \\
\text { central injection tube }\end{array}$ & 6 & 10 & 4 & 3.5 \\
\hline
\end{tabular}

Four concrete blocks (specimens 1\#-4\#) had no fractures and were used to simulate porous reservoir rocks and the remaining blocks containing pre-existing fractures (specimens $5 \#-8 \#)$ were used to simulate fractured reservoir rocks. The pre-fractures in specimens $5 \#-6 \#$ were parallel to the central injection tube and $5 \mathrm{~cm}$ apart. The pre-fracture in specimen $7 \#$ was parallel to and intersecting the central injection tube (Fig.
2 ), while the pre-fracture in specimen $8 \#$ was perpendicular to and intersecting the central injection tube, as shown in Fig. 3.

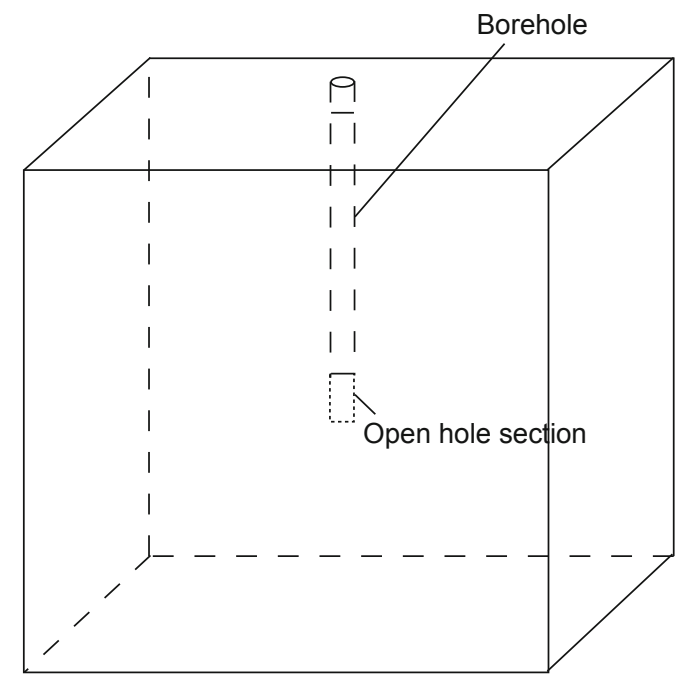

Fig. 1 Schematic of the specimen configuration for hydraulic fracture tests

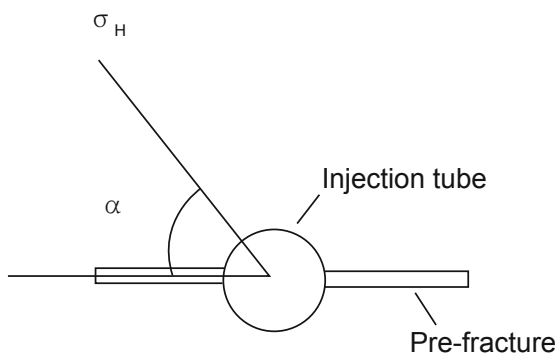

Fig. 2 Pre-fracture in specimen $7 \#$

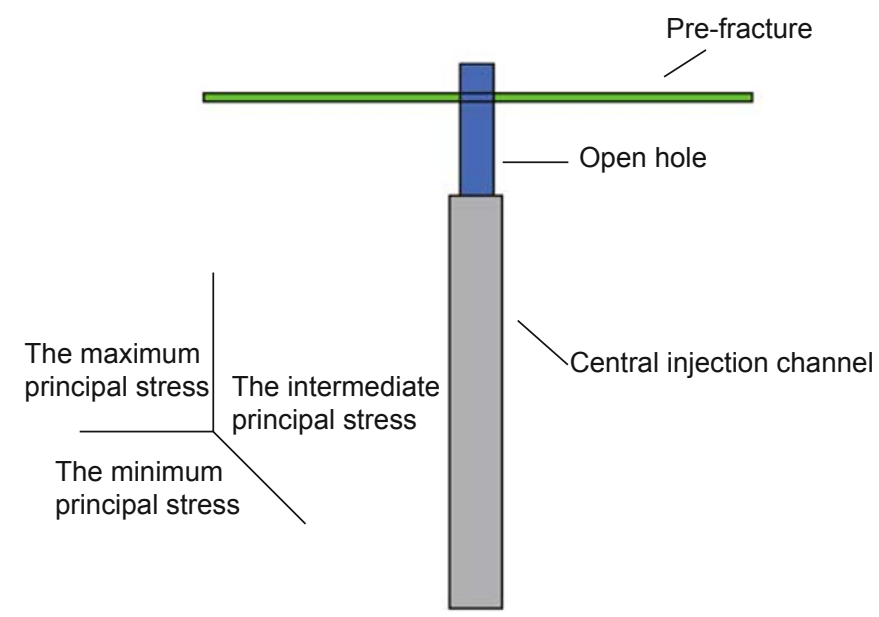

Fig. 3 Pre-fracture in specimen $8 \#$

\section{Results and discussion}

\subsection{Specimens containing no fractures}

Hydraulic fracturing tests were conducted on specimens 1\#-4\#, which had no fractures, to study the initiation and propagation of hydraulic fracture in porosity reservoirs. The 
pressure response in the borehole is illustrated in Fig. 4. The pressure response curve can be described as four stages: a fluid injection stage $(A B)$, pressure holding stage $(B C)$, pressure releasing stage $(C D)$, and the fracture propagation stage $(D F)$. The peak (point $C$ ) represents the fracture initiation point, i.e., the creation of a fracture. The borehole pressure drops instantaneously at this point duo to the fluid leak-off through the induced fracture face and finally reaches the lowest value (point $D$ ). The highest value of extension pressure reached is point $E$.
Four specimens were all fractured, and their borehole pressure responses are similar to that shown in Fig. 4. The induced fractures initiated in the direction normal to the smallest horizontal principal stress. As Fig. 4 shows, the fracture pressure was apparently higher than the fracture extension pressure. This indicates that the stress was concentrated around the wellbore, in the range of 3-6 times the wellbore diameter, i.e. $1 / 10-1 / 5$ of the specimen size. Out of this range, it is considered that the far-field stress played a major part. The data of four specimens is given in Table 2 .

Table 2 Critical pressure values and the hydraulic fracture orientation measured in the porous specimens

\begin{tabular}{cccccc}
\hline Specimen & $\begin{array}{c}\text { Tensile strength } \\
\mathrm{MPa}\end{array}$ & $\begin{array}{c}\text { Fracture pressure } \\
\text { (point } C \text { ), } \mathrm{MPa}\end{array}$ & $\begin{array}{c}\text { Lowest pressure } \\
\text { (point } D \text { ), } \mathrm{MPa}\end{array}$ & $\begin{array}{c}\text { Extension pressure } \\
\text { (point } E \text { ), } \mathrm{MPa}\end{array}$ & Orientation of the hydraulic fracture \\
\hline $1 \#$ & 5.05 & 14.72 & 7.05 & 8.47 & Perpendicular to the minimum principal stress \\
$2 \#$ & 5.04 & 13.88 & 6.45 & 8.65 & Perpendicular to the minimum principal stress \\
$3 \#$ & 5.29 & 14.61 & 6.48 & 8.12 & Perpendicular to the minimum principal stress \\
$4 \#$ & 5.44 & 14.49 & 6.30 & 8.96 & Perpendicular to the minimum principal stress \\
\hline
\end{tabular}

The fracture pressure $p_{\mathrm{f}}$ can be calculated by the Hubbert and Willis formula (Hubbert and Willis, 1957):

$$
p_{\mathrm{f}}=3 \sigma_{\mathrm{h}}-\sigma_{\mathrm{H}}-p_{\mathrm{P}}+S_{\mathrm{t}}
$$

where $\sigma_{\mathrm{h}}$ is the minimum horizontal stress, $\mathrm{MPa} ; \sigma_{\mathrm{H}}$ is the maximum horizontal stress, $\mathrm{MPa} ; p_{\mathrm{P}}$ is the pore pressure, $\mathrm{MPa} ; S_{\mathrm{t}}$ is the tensile strength of the concrete specimens.

Due to the low porosity of the concrete specimens, no fluid can flow in the specimens, so the pore pressure can be regarded as zero.

When the hydraulic fracture extends beyond the vicinity of the wellbore, the fracture propagation is dominated by the far-field stress. The fracture extension pressure can be calculated by the following equation:

$$
p_{\mathrm{re}} \approx \sigma_{\mathrm{h}}+S_{\mathrm{t}}
$$

The fracture pressure and extension calculated from Eqs. (1) and (2) are listed in Table 3.

Table 3 Analytical results of experimental data

\begin{tabular}{ccc}
\hline Specimen & $\begin{array}{c}\text { Fracture pressure } \\
p_{\mathrm{f}}, \mathrm{MPa}\end{array}$ & $\begin{array}{c}\text { Extension pressure } \\
p_{\mathrm{r}}, \mathrm{MPa}\end{array}$ \\
\hline $1 \#$ & 11.14 & 9.14 \\
$2 \#$ & 10.67 & 8.67 \\
$3 \#$ & 11.06 & 9.06 \\
$4 \#$ & 10.85 & 8.85 \\
\hline
\end{tabular}

The fracture pressure calculated from Eq. (1) was lower than the experimental value. The average relative deviation was $24 \%$, which indicates that Eq. (1) is not applicable to the analysis of hydraulic fracturing tests. The average deviation between the extension pressure calculated from Eq. (2) and the experimental value was $4.2 \%$, which indicates that the resistance force required to be overcome to drive fracture propagation in the porous specimens is very close to the value in deep formations.

The fractured section of specimen $3 \#$ is shown in Fig. 5. As can be seen from the figure, the fracture face is symmetrical and planar, but locally uneven. For the color distribution, the shade of red varied. The red color was darker near the fluid injection tube and on the right side of the specimen. The color of the left side became lighter. The distribution of injection fluid was not uniform. Based on the principle that the longer time the fracture face contacted with the fracture fluid, the darker the color of the fracture face we observed, the initiation and propagation of fractures could be analyzed.

Hydraulic fracture initiation is dependent on the injection pressure, which has to overcome stress concentration around the borehole, and the fracture fluid is forced into the fractures. The specimen begins to fracture. However, the specimen did not break into two parts at a time by the hydraulically-induced fracture, instead a fracture was formed near the borehole.

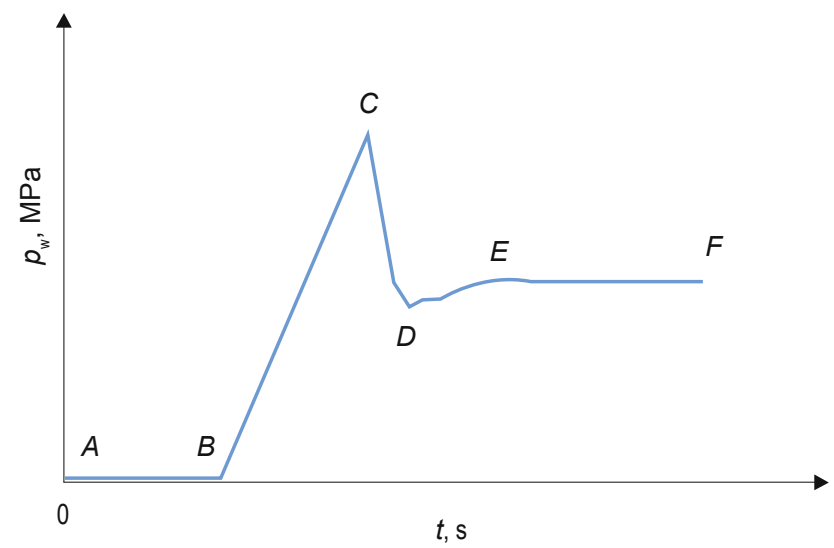

Fig. 4 Pressure response during hydraulic fracturing 


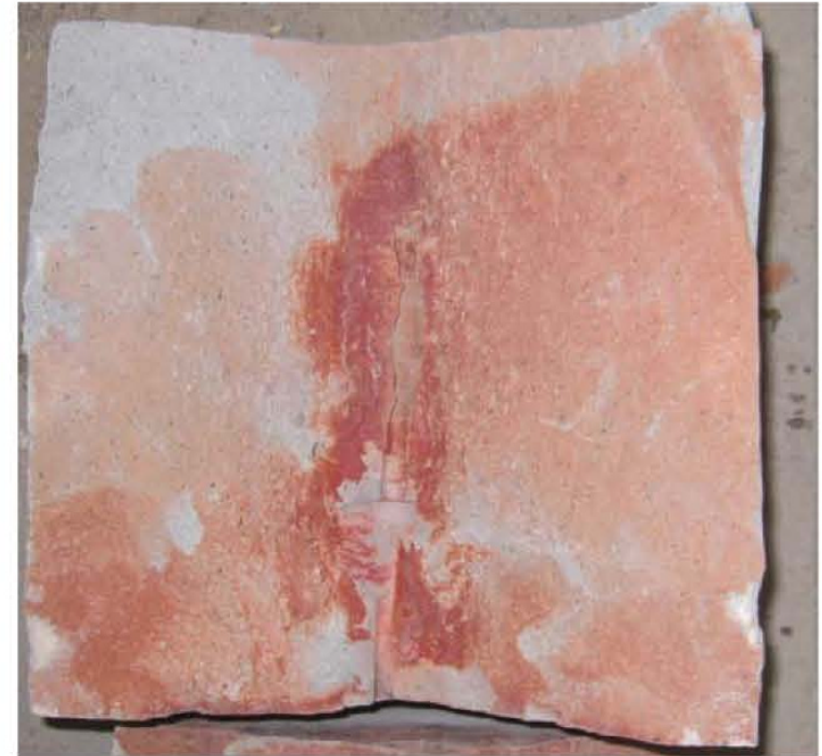

Fig. 5 Fracture propagation in specimen $3 \#$
This phenomenon was mainly due to low pump capacity and the limitation of energy capacity. The fracture opening caused a pressure decrease, as the segment $C D$ on the Fig. 2. The fracture continued to extend to the specimen surface when the fracture was filled with the fracture fluid.

\subsection{Specimens containing pre-existing fractures}

The specimens containing pre-existing fractures were used to simulate fractured reservoir rocks. Due to the complexity of naturally fractured systems, it is difficult to determine the influence of natural fractures on the initiation and propagation of fractures during hydraulic fracturing. In this study, the specimens we used to study the interaction between hydraulically-induced and pre-existing fractures had only one pre-existing fracture. Four tests were conducted and all specimens were fractured. The crack orientation followed the principle mentioned above and the overall trend of the fracturing curve is still as shown in Fig. 4, though the disturbance of natural fractures was very serious. The data of the fracturing curve is shown in Table 4.

Table 4 Critical pressure values and the hydraulic fracture orientation measured in the fractured specimens

\begin{tabular}{ccccc}
\hline Specimen & $\begin{array}{c}\text { Fracture pressure } \\
\text { (point } C \text { ), } \mathrm{MPa}\end{array}$ & $\begin{array}{c}\text { Lowest pressure } \\
\text { (point } D \text { ), } \mathrm{MPa}\end{array}$ & $\begin{array}{c}\text { Extension pressure } \\
\text { (point } E \text { ), } \mathrm{MPa}\end{array}$ & Orientation of the hydraulic fracture \\
\hline $5 \#$ & $11 . .46$ & 3.61 & 4.15 & Narrow single-wing fracture, perpendicular to the minimum principal stress \\
$6 \#$ & 12.01 & 3.72 & 4.76 & Narrow single-wing fracture, perpendicular to the minimum principal stress \\
$7 \#$ & 8.42 & 4.72 & 6.45 & Symmetrical fractures, perpendicular to the minimum principal stress \\
$8 \#$ & 9.95 & 6.57 & 7.83 & Fracture perpendicular to the maximum principal stress, and having a tendency to turn
\end{tabular}

Table 4 shows that the fracture pressure of specimens $5 \#$ and $6 \#$ was close to that of the specimens without pre-existing fractures, which could be calculated by Eq. (1). The average relative deviation was $6.8 \%$. The extension pressure was low and close to the minimum principal stress, which could not be calculated by Eq. (2). For specimens $7 \#$ and $8 \#$, because the open hole intersected with the pre-fracture, the fracture pressure was low and the extension pressure was close to that of the specimens $5 \#$ and 6\#, which could not be forecast by Eq. (1) and Eq. (2). The fracturing tests on specimens containing pre-fractures indicate that the pre-existing fracture had significant impact on the initiation and propagation of hydraulically-induced fractures.

Fig. 6 shows that the hydraulic fracture propagated in the direction perpendicular to the minimum horizontal principal stress and then was diverted or arrested by the natural fracture normal to it. Finally a ribbon-like fracture was formed on the face without the pre-existing fractures and propagated to the fringe of the sample.

In this test, the hydraulic fracture would merge into the natural fracture plane when the hydraulic fracture was arrested by the natural fracture face having bigger edge extension. The hydraulic fracture geometry (symmetrical wings) would be changed and the fracture would continue to extend in a new form along the preferred plane that was easily broken. Finally a banded narrow fracture was formed.

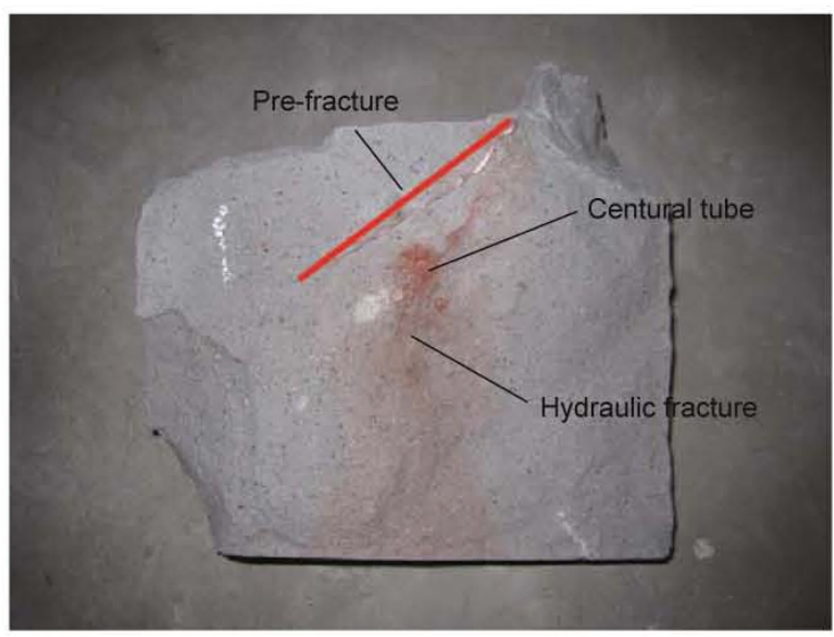

Fig. 6 Fracture propagation in specimen $5 \#$

In specimen $7 \#$, the pre-existing fracture face was the easiest plane to expand because of the included angle between the fracture and the minimum horizontal principal stress and zero tensile strength of the fracture. The hydraulicallyinduced fracture in specimen $7 \#$ was on the verge of the pre-existing fracture, and initiated and propagated along the face perpendicular to the minimum horizontal principal stress. Its geometry was similar to that hydraulically induced in specimens $1 \#-4 \#$. However, its fracture pressure 
was significantly low. This can be explained as the preexisting fracture could reduce and eliminate the original stress concentration around the open hole. The stress state of surrounding rock is the main factor influencing fracture initiation near the borehole.

Fig. 7 shows the fracture morphology in specimen 8\#. The hydraulic fracture initiated in the direction of the preexisting fracture, i.e. perpendicular to the maximum principal stress, and gradually turned to the direction perpendicular to the minimum principal stress. It is very different from the fracture geometry in specimen $7 \#$.

Both specimens $7 \#$ and $8 \#$ had a fracture in the borehole wall. The pre-existing fracture in specimen $7 \#$ was parallel to the maximum principal stress, and then formed included angles with the intermediate principal stress and the minimum principal stress, respectively. The fracture in specimen $8 \#$ was perpendicular to the maximum principal stress. The fracture pressure for these two tests was very low, about two thirds that of the specimens without fractures. The fracture pressure of specimen $8 \#$ was relatively higher than that of the specimen $7 \#$. The experimental results indicate that the preexisting fracture (on the borehole wall) played a great part in the fracture initiation. The fracture in the specimens reduced and eliminated the effect of the stress state of the surrounding rock.

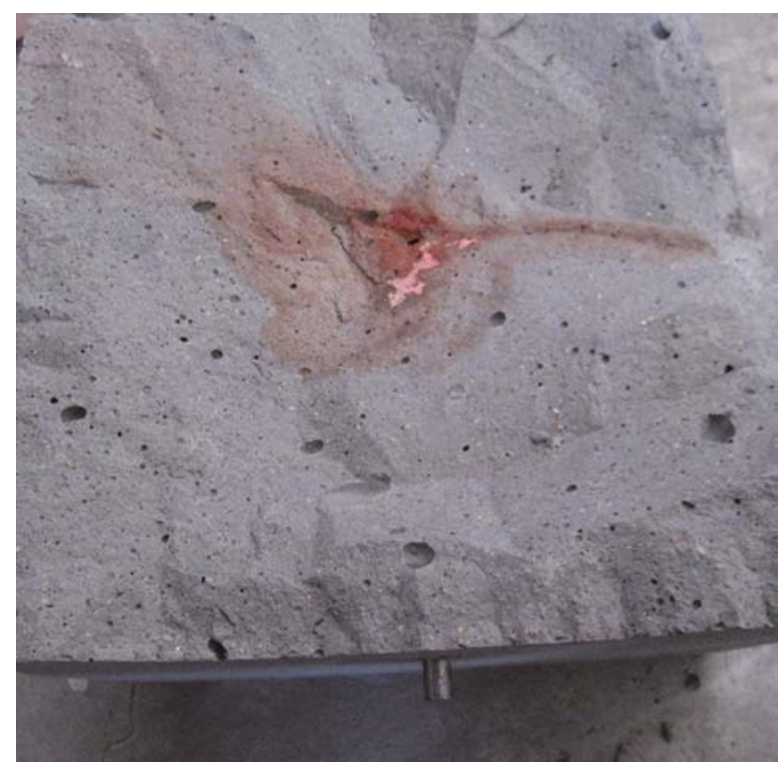

Fig. 7 Fracture propagation in specimen $8 \#$

\section{Conclusions}

1) The distribution of crustal stress, the stress state around the wellbore, and reservoir types are the important factors influencing fracture initiation. Crustal stress acts mainly in the area far from the wellhole and affects the fracture initiation. The stress state of the surrounding rock acts mainly in the area near the hole and affects the fracture propagation. Reservoir types may affect the stress state of surrounding rock and the fracture initiation and propagation.

2) Natural fractures in reservoirs have a significant effect on the fracture initiation. They influence the fracture pressure and the fracture geometry. The natural fractures would reduce the rock fracture pressure and make the fracture geometry complicated.

3) Natural fractures in the borehole wall would eliminate the stress concentration around the borehole and reduce the fracture initiation pressure drastically. Here, the in-situ stress (tectonic stress) became a dominant factor in influencing the fracture geometry.

4) Hydraulically-induced fractures tended to propagate along the fracture occurrence direction. When the hydraulic fracture intersected with the natural fracture, the hydraulic fracture continued to extend along the direction without natural fractures. When the natural fractures existed in the wall, the hydraulic fracture initiated along the direction of the natural fracture and gradually turned to the direction normal to the minimum principal stress.

\section{Acknowledgements}

This study was supported by the National Natural Science Foundation of China (No. 50974029), the Doctoral Program of the Ministry of Education (No. 20070220001), and Province Natural Science Foundation of Heilongjiang of China (No. E200816).

\section{References}

Beugelsdijk L J L, de Pater C J and Sato K. Experimental hydraulic fracture propagation in a multi-fractured medium. Paper SPE 59419 presented at the SPE Asia Pacific Conference On Integrated Modeling for Asset Management, 25-26 April 2000, Yokohama, Japan

Blanton T L. Propagation of hydraulically and dynamically induced fractures in naturally fractured reservoirs. Paper SPE 15261 presented at the Unconventional Gas Technology Symposium, 18-21 May 1986, Louisville Kentucky

Chen M, Chen Z X and Huang R Z. Hydraulic fracturing of highly deviated wells. Journal of University of Petroleum, China. 1995. 19(2): 30-35 (in Chinese)

Chen M, Pang F and Jin Y. Experiments and analysis on hydraulic fracturing by a large-size triaxial simulator. Chinese Journal of Rock Mechanics and Engineering. 2000. 19(Supp.): 868-872 (in Chinese)

Daneshy A A. Hydraulic fracture propagation in the presence of planes of weakness. Paper SPE 4852 presented at the SPE European Spring Meeting, 29-30 May 1974, Amsterdam, the Netherlands

Hubbert M K and Willis D G. Mechanics of hydraulic fracturing. Journal of American Association of Petroleum Geologists. 1957. 12(18): 239-257.

Jin Y, Zhang X D and Chen M. Initiation pressure models for hydraulic fracturing of vertical wells in naturally fractured formations. Acta Petrolei Sinica. 2005. 26(6): 113-118 (in Chinese)

Mahrer K D, Aud W W and Hansen J T. Far-field hydraulic fracture geometry: A changing paradigm. Paper SPE 36441 presented at the SPE Annual Technical Conference and Exhibition, 6-9 Oct. 1996, Denver, Colorado, U.S.A.

Thiercelin M, Naceur K B and Lemanczyk Z R. Simulation of threedimensional propagation of a vertical hydraulic fracture. Paper SPE 13861 presented at the SPE/DOE Low Permeability Gas Reservoirs, 19-22 May 1985, Denver, Colorado

Warpinski N R and Teufel L W. Influence of geologic discontinuities on hydraulic fracturing propagation. JPT. 1987, 28(3): 209-220

Yew C H and Li Y. Fracturing of a deviated wells. Paper SPE 16930 
presented at SPE Annual Technical Conference and Exhibition, 2730 Sept 1987, Dallas

Yew C H. Pore fluid and wellbore stabilities. Paper SPE 23881 presented at SPE International Meeting on Petroleum Engineering, 24-27 March 1992, Beijing, China

Yu X Y, Xing J G and Wang X Y. Research on fracturing pressure and azimuth of a deviated well. Journal of Jianghan Petroleum Institute. 1994. 16(3): 57-60 (in Chinese)
Zhang G Q and Chen M. Non-planar propagation of hydraulic fracture near horizontal wellbore. Acta Petrolei Sinica. 2005. 26(3): $95-97$ (in Chinese)

Zhou J, Chen M, Jin Y, et al. Experimental study of propagation mechanism of hydraulic fracture in naturally fractured reservoir. Acta Petrolei Sinica. 2007. 28(5): 109-113 (in Chinese)

(Edited by Sun Yanhua) 